Article

\title{
Xylan-Derived Light Conversion Nanocomposite Film
}

\author{
Yunyi Yang, Yushuang Zhao, Yijie Hu, Xinwen Peng and Linxin Zhong * \\ State Key Laboratory of Pulp and Paper Engineering, South China University of Technology, Guangzhou 510641, \\ China; 201730440313@mail.scut.edu.cn (Y.Y.); 15574930182m0@sina.cn (Y.Z.); \\ 201710104846@mail.scut.edu.cn (Y.H.); fexwpeng@scut.edu.cn (X.P.) \\ * Correspondence: lxzhong0611@scut.edu.cn
}

Received: 11 July 2020; Accepted: 5 August 2020; Published: 9 August 2020

check for updates

\begin{abstract}
A new type of sustainable light conversion nanocomposite film was fabricated by using carboxymethyl xylan as matrix and xylan-derived carbon dots (CDs) as both light conversion regents and nano reinforcements. The results demonstrate that CDs can not only significantly enhance the mechanical strength of the nanocomposite film because of chemical reaction between CDs and carboxymethyl xylan, but also impart the film with excellent optical properties. With $1.92 \mathrm{wt} \% \mathrm{CDs}$, the tensile strength and elastic modulus of the film are increased by $114.3 \%$ and $90.7 \%$, respectively. Moreover, the film has typical excitation and emission spectra, enabling the efficient absorption of UV and the conversion of UV to blue light. This xylan-derived light conversion nanocomposite film is expected to be used in agricultural planting and food packaging.
\end{abstract}

Keywords: hemicelluloses; xylan; biomass; hydrothermal; carbon dots

\section{Introduction}

Light conversion film is a kind of functional film that can change the wavelength of light [1], and shows great potential in the fields of agriculture [2], food industry [3], skin care [4], and so on. For example, red light and blue light can be absorbed by plants to facilitate chlorophyll synthesis, while ultra-violet (UV) components in sunlight cannot be utilized and will induce pathological changes of plants [2]. Thus, it is of great significance to use light conversion film to convert UV to blue light to protect plants and boost their growth. The UV absorption of dairy foods, such as milk products, can result in significant loss of valuable nutrients and discoloration, as well as formation of strong off-flavors [3]. Additionally, UV is also harmful to human skin and can cause erythema and skin cancel. Therefore, light conversion film is highly required to protect our foods and skin from UV radiation [5].

Light conversion film is composed of light conversion agent and matrix, where light conversion agent acts as a pivotal role [1]. Conventional light conversion agents are mostly organic dyes, such as triphenylacrylonitrile [6] and perylene diimides [7]. However, these organics are toxic and easily degraded under light [8]. On the other hand, most of inorganic photoactive materials, such as nano $\mathrm{ZnO}$ and $\mathrm{TiO}_{2}$, easily aggregate at a certain concentration, reducing the transparency of final films [9]. Carbon dots (CDs) are a new type of light conversion agents that can effectively absorb certain characteristic wavelength and allow electrons to transform from ground state to excited state. Meanwhile, a part of energy is released in the form of photons when transition from the lowest excited state to the ground state, and thus the whole process of sunlight conversion is completed [1]. CDs from renewable biomass [10], such as wheat straw [11], grass [12], protein [13,14], chitosan [15], cellulose fiber [16], lignin [17], and hemicelluloses [18], are especially attractive and become alternatives to conventional light conversion agents due to their high light conversion, sustainability, and low cost.

Conventional matrixes are mainly petrochemicals, such as polythene [19] and polyvinyl chloride [6], because of their excellent film formation, good mechanical properties, and transparency. However, 
the nonrenewability and nonbiodegradability of these synthetic polymers pose a great hazard to environment. Renewable biomass resources, including hemicelluloses [20], cellulose [21,22] and chitosan [23], are environmental-friendly, biodegradable, and biocompatible, making them attractive matrixes for light conversion films. Up to now, there has been a few composite films fabricated by combining biomass resources such as cellulose [24] or chitosan [25] and CDs for biomedicine application [24-28]. For example, Yu et al. [24] fabricated a CD-glucose oxidase/cellulose acetate film (L-cysteine and citric acid monohydrate as precursors to synthesize CDs) that exhibited high sensitivity when being used as an optical fiber glucose biosensor. Cuevas et al. [26] obtained a luminescent cellulose film with improved electrical conductivity and mechanical strength by incorporating different silicon-dot and CDs (from lactose) into cellulose matrix. However, light conversion film based on biomass-derived CDs and biomass matrix has rarely been investigated.

Hemicelluloses such as xylan or glucomannan are the secondly abundant polysaccharides in plants, accounting for 20-30 wt \% in dry plants. However, the relatively low molecular weight of hemicelluloses usually leads to poor mechanical performances [29]. Chemical modification can improve the film-forming and mechanical performances of hemicelluloses [30]. However, up to now, hemicelluloses/CDs film has not been reported. Herein, a xylan-derived light conversion film was fabricated by using carboxymethyl xylan as matrix and xylan-derived CDs as light conversion regents and nano reinforcements. The interaction between matrix and CDs was revealed. The important roles of CDs on imparting the film with light conversion performances and enhancing the mechanical strength of film were investigated.

\section{Materials and Methods}

\subsection{Materials}

Xylan (weight-average molecular weight $M_{\mathrm{w}}=133,692$ ), which was kindly supplied from Shandong Longlive Co., Ltd., contains $85.4 \%$ xylose, $6.3 \%$ arabinose, $1.5 \%$ galactose, $3.2 \%$ glucose, $2.2 \%$ galacturonic acid. Quinine sulfate dehydrate $(99.0 \%$, Biotech), sodium hydroxide (ACS, $97.0 \%)$, hydrochloric acid $(36 \% \sim 38 \%)$, sodium chloroacetate, acetic acid glacial were of analytical grade and bought from Aladdin (China). Polyvinyl alcohol (PVA) $\left(M_{\mathrm{w}}: 30,000-70,000\right)$ was bought from Sigma-Aldrich. Water was ultrapure (R: $18.2 \mathrm{M} \Omega \cdot \mathrm{cm})$.

\subsection{Preparation of $C D s$}

CDs were prepared according to our previous method [16]. Firstly, $1.5 \mathrm{~g}$ xylan was dispersed in ultrapure water $(30 \mathrm{~mL})$ by stirring before being transferred to stainless steel autoclaves (SLM-50). The hydrothermal reaction was carried out in a furnace under $600 \mathrm{rpm}$ at $240{ }^{\circ} \mathrm{C}$ for $6 \mathrm{~h}$. After cooling to room temperature, thoroughly washing with deionized water, and drying in a vacuum oven at $80^{\circ} \mathrm{C}$, hydrothermal carbon (HTC) was obtained. Then, $50 \mathrm{mg}$ HTC was added into $50 \mathrm{~mL}$ Teflon-lined stainless-steel autoclave (SLM-50) with $25 \mathrm{~mL} 0.1 \mathrm{M} \mathrm{NaOH}$. The chamber was sealed and $\mathrm{O}_{2}$ was blown into the autoclave to remove air. Afterwards, the autoclave (with $1 \mathrm{MPa}_{2}$ ) was heated at $160{ }^{\circ} \mathrm{C}$ for $1 \mathrm{~h}$ with stirring (1000 rpm). After naturally cooling to room temperature, a yellow suspension was obtained and neutralized by $\mathrm{HCl}$. The mixture was filtered using $0.22 \mu \mathrm{m}$ microporous film and the filtrate was dialyzed in a dialysis bag (retaining molecular weight $=500 \mathrm{Da}$ ) in deionized water for 5 days (replacing fresh water for $12 \mathrm{~h}$ ). Finally, the suspension was freeze-dried to obtain pure CDs.

\subsection{Preparation of Carboxymethylated Xylan (CX)}

$6.6 \mathrm{~g}$ xylan was suspended in $60 \mathrm{~mL} 20 \%$ ethanol solution by violent stirring. After heating the mixed solution to $30{ }^{\circ} \mathrm{C}, 32.88 \mathrm{~mL} 25 \% \mathrm{NaOH}$ solution was slowly added and stirred for $30 \mathrm{~min}$. $23 \mathrm{~g}$ sodium monochloroacetate was added to the mixed solution and heated to $65{ }^{\circ} \mathrm{C}$ for $2 \mathrm{~h}$. Then, $32.88 \mathrm{~mL} 25 \% \mathrm{NaOH}$ solution and $23 \mathrm{~g}$ sodium monochloroacetate was added slowly, and the 
reaction was processed for $1 \mathrm{~h}$ at $65{ }^{\circ} \mathrm{C}$. The precipitate was subsequently filtered and washed thoroughly with $75 \%$ ethanol. Finally, CX was obtained by freeze-drying the precipitate.

\subsection{The Degree of Substitution (DS) of Carboxyl Group in CX}

The degree of substitution (DS) of carboxyl group in CX was measured by a conductivity method. $0.1 \mathrm{~g} \mathrm{CX}$ was dissolved in $100 \mathrm{~mL} \mathrm{NaCl}$ solution and the $\mathrm{pH}$ of the solution was adjusted to 4 by $0.1 \mathrm{M}$ hydrochloric acid. After adding $0.01 \mathrm{M} \mathrm{NaOH}$ standard solution in nitrogen atmosphere, the change of conductivity was recorded. The DS of CX was calculated by Formulas (1) and (2):

$$
\begin{gathered}
B=M\left(V_{2}-V_{1}\right) / m \\
D S=0.132 \times B /(1-0.008 \times B)
\end{gathered}
$$

where $\mathrm{m}$ is the weight of $\mathrm{CX}(\mathrm{g}), \mathrm{M}$ is the standard molar concentration of $\mathrm{NaOH}(\mathrm{mol} / \mathrm{L}), \mathrm{V}_{1}$ is the volume of $\mathrm{NaOH}$ at the left isoelectric point $(\mathrm{mL}), \mathrm{V}_{2}$ is the volume of $\mathrm{NaOH}$ at the right isoelectric point $(\mathrm{mL})$, and $\mathrm{B}$ is the $\mathrm{NaOH}$ consumed per gram of $\mathrm{CX}(\mathrm{mmol} / \mathrm{g})$. The DS of carboxyl group is 0.43 .

\subsection{Preparation of CX/PVA-CDs Composite Films}

$13 \mathrm{~mL}$ ultrapure water, $0.4 \mathrm{~g} \mathrm{CX}$ and $0.1 \mathrm{~g}$ PVA were mixed homogeneously, followed by adding different contents of CDs $(0,0.48,0.96,1.44$, and $1.92 \mathrm{wt} \%$, based on the total mass of $\mathrm{CX}$ and PVA). The mixture was stirred at $80^{\circ} \mathrm{C}$ for $1 \mathrm{~h}$. After reaction, the mixture was cooled down to room temperature and then poured into a polyethylene Petri dish with a diameter 0 $9.0 \mathrm{~cm}$. Composite films were obtained after drying the mixture at room temperature. The as-prepared composite films were named as CX/PVA, CX/PVA-CDs ${ }_{0.48}, \mathrm{CX} / \mathrm{PVA}^{-C D s_{0.96}}, \mathrm{CX} / \mathrm{PVA}-\mathrm{CDs}_{1.44}$, and CX/PVA-CDs 1.92 , respectively.

\subsection{Characterizations}

Transmission electron microscopy (TEM) and the high-resolution transmission electron microscopy (HR-TEM) images were obtained using a JEM-2100F at $200 \mathrm{kV}$. Samples for TEM measurements were prepared by placing a drop of the colloidal solution of CDs on a carbon-coated copper grid and then dried at room temperature. Scanning electron microscopy (SEM, ZEISS Merlin) and atomic force microscopy (AFM, Nanoscope 3a) were used to observe the morphology of the composite films. The sample was mixed with $\mathrm{KBr}$ powder at a weight ratio of 1: 100, grinded and pressed into tablet for Fourier transform infrared spectroscopy (FTIR, VERTEX 70, Bruker Corp.). Thermo Gravimetric Analyzer (TGA, TA Q500) was used to measure the thermal properties of samples in $\mathrm{N}_{2}$ atmosphere. The temperature was first raised to $100{ }^{\circ} \mathrm{C}$ for $5 \mathrm{~min}$ to remove physical adsorbed water, and then to $700{ }^{\circ} \mathrm{C}$ with a heating rate of $15^{\circ} \mathrm{C} / \mathrm{min}$. The ultraviolet visible (UV-VIS) absorption spectrum and transparency of films were measured on UV-VIS Spectrometer (s3100). The fluorescence property was performed on Fluorescence spectrometer (HORIBA Scientific FluoroMax-4). After placing these films in a laboratory with constant temperature and humidity $\left(23{ }^{\circ} \mathrm{C}\right.$ and $50 \%$ relative humidity) for $24 \mathrm{~h}$, the mechanical properties were carried out on Instron 3342. The size of the tested samples was $15 \times 60 \mathrm{~mm}$, and five pieces were tested for each sample. Breaking strength, elongation, and modulus of elasticity were calculated from the average of tensile data.

\section{Results and Discussion}

\subsection{Surface Morphology of the Composite Films}

The as-prepared xylan-derived CDs exhibit bright blue-green fluorescence under $365 \mathrm{~nm}$ UV light (the inset in Figure 1a). The typical TEM image (Figure 1a) shows that CDs are uniform and well dispersed in water, with a narrow size distribution of 1.0-3.5 $\mathrm{nm}$ in diameter (Figure 1c). HR-TEM 
(Figure $1 \mathrm{~b}$ ) reveals clear lattice fringes with a space of $0.21 \mathrm{~nm}$, which corresponds to the (100) diffraction planes of graphite [14].
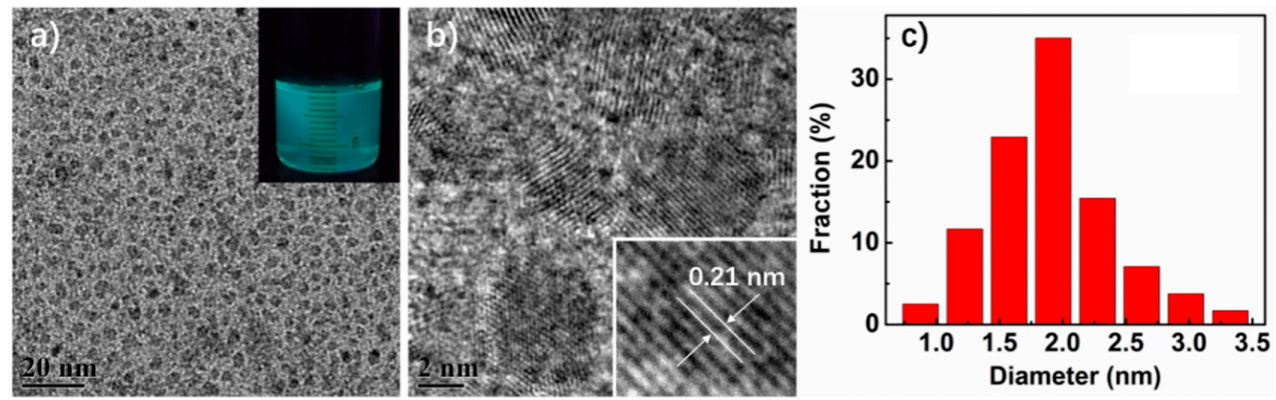

Figure 1. (a) TEM image (the inset is the CDs suspension under $365 \mathrm{~nm}$ UV); (b) HR-TEM image; (c) particle size distribution of CDs calculated from TEM image.

Xylan was carboxymethylated (DS $=0.43, M_{\mathrm{w}}=88,541$ ) to improve its water solubility and thus obtain homogeneous CX/CD mixture. PVA was introduced to improve the film-formation performance of CX. As shown in Figure 2a, CX/PVA is transparent and shows smooth surface, indicating good compatibility between CX and PVA; while the nanocomposite films (CX/PVA-CDs, Figure 2b-e) slightly turn yellow with good transparency after adding CDs. AFM image demonstrates that the surface of CX/PVA is compact and uniform, while the surfaces of CX/PVA-CDs become rough and uneven. The increased roughness of the composite film can be attributed to the presence of CDs on the surface of film [28].

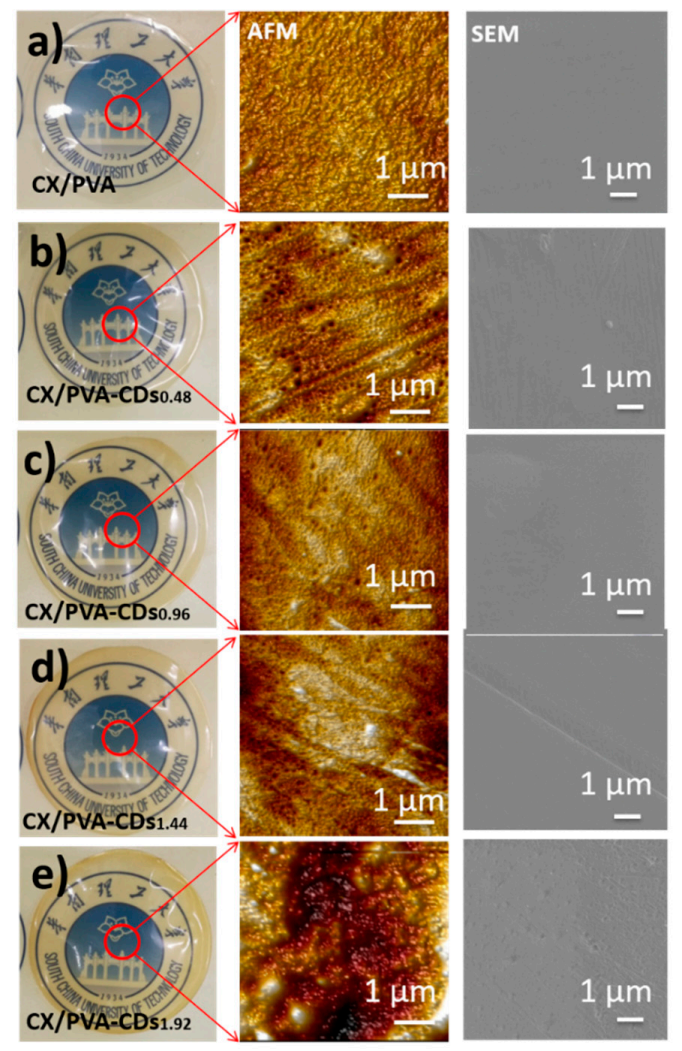

Figure 2. Digital images, atomic force microscopy (AFM) images, and SEM images of CX/PVA and CX/PVA-CDs: (a) CX/PVA; (b) CX/PVA-CDs 0.48 ; (c) CX/PVA-CDs 0.96 ; (d) CX/PVA-CDs 1.44 ; (e) CX/PVA-CDs 1.92 . 


\subsection{FT-IR and TG Analyzations}

Figure 3 illustrates the FT-IR spectra of CDs, CX/PVA, and CX/PVA-CDs. The peak located at $3300-3400 \mathrm{~cm}^{-1}$ corresponds to the O-H absorption of xylan and PVA [31]. The bands at $2927 \mathrm{~cm}^{-1}$ and $840 \mathrm{~cm}^{-1}$ are attributed to the stretching vibration of $-\mathrm{CH}_{2}$. The vibration peak at $840 \mathrm{~cm}^{-1}$ is caused by the vibration of $\mathrm{C}-\mathrm{C}$ in xylan skeleton and the benzene ring skeleton in CDs. In the spectrum of $C D$ s, the peaks at $1760,1580,1380 \mathrm{~cm}^{-1}$ are assigned to the vibration of $\mathrm{C}=\mathrm{O}$, the stretching vibration of aromatic $\mathrm{C}=\mathrm{C}$ bond and the symmetric deformation vibration of $\mathrm{C}-\mathrm{H}$ bond in methyl, respectively [18,32]. For CX/PVA, the adsorption at about $1740 \mathrm{~cm}^{-1}$ can be ascribed to the stretching vibration of ester functional group $\mathrm{C}=\mathrm{O}[33,34]$. The bands at 1080 and $1250 \mathrm{~cm}^{-1}$ are caused by symmetric and asymmetric stretching vibration of $\mathrm{C}-\mathrm{O}-\mathrm{C}$, respectively [35]. The peaks at 1409 and $1580 \mathrm{~cm}^{-1}$ confirm the symmetric and asymmetric stretching vibrations of carboxyl ion $-\mathrm{CO}_{2}-$ in $\mathrm{CX}$, indicating the successful carboxymethylation of xylan. In the spectra of CX/ PVA-CDs, the peak at $1580 \mathrm{~cm}^{-1}$ disappears and the peak at $1409 \mathrm{~cm}^{-1}$ weakens, which proves that $C D$ san react with $-\mathrm{CO}_{2}-$. With the rise of CDs content, the intensities of bands at 1740, 1250, and $1080 \mathrm{~cm}^{-1}$ increase, suggesting that the hydroxyl groups in CDs react with the carboxyl ions in CX to form new ester bond.

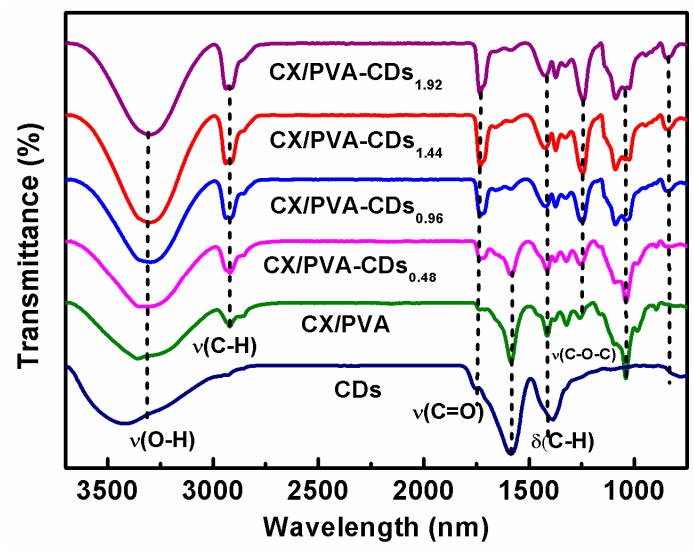

Figure 3. FT-IR spectra of CDs, CX/PVA, and CX/PVA-CDs.

Figure 4 shows that the mass loss of composite films mainly occurs at $220-325^{\circ} \mathrm{C}$, and the maximum degradation rate happens at about $297^{\circ} \mathrm{C}$. Although the weight retention of nanocomposite film at $700{ }^{\circ} \mathrm{C}$ is not closely related to CDs content (may be due to the low CDs loading), the nanocomposite films exhibit higher weight retentions than CX/PVA. As illustrated in Figure $4 \mathrm{~b}$, the initial degradation temperatures of CX/PVA, CX/PVA-CDs ${ }_{0.48}, \mathrm{CX} / \mathrm{PVA}^{-\mathrm{CDs}_{0.96}}, \mathrm{CX} / \mathrm{PVA}-\mathrm{CDs}_{1.44}$, and CX/PVA-CDs 1.92 are $257,261,260,261$, and $260^{\circ} \mathrm{C}$, respectively, indicating that the initial degradation temperatures of CX/PVA-CDs slightly increase, which can be attributed to the chemical bonds between CDs and CX.
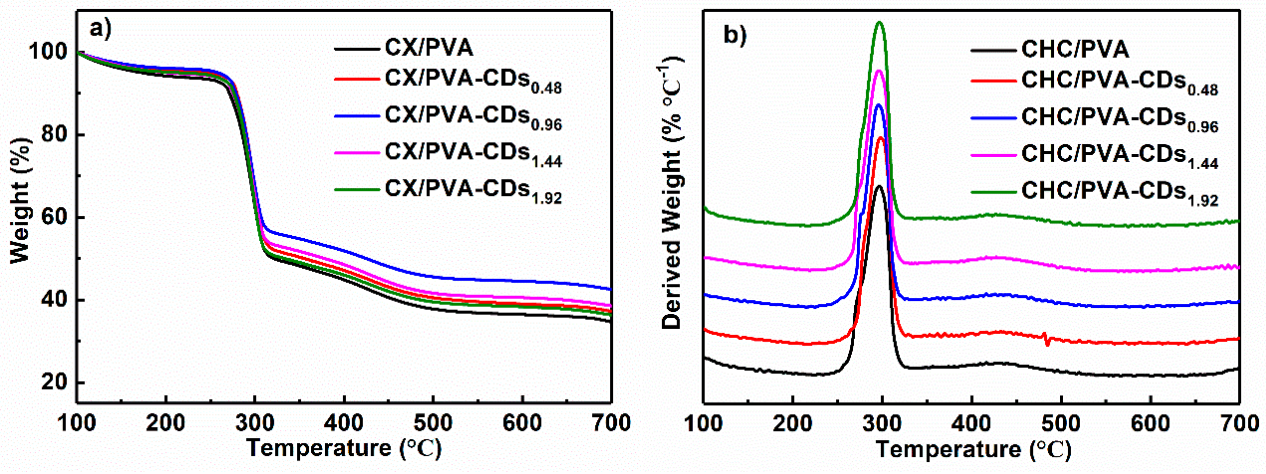

Figure 4. (a) TG curves of CX/PVA and CX/PVA-CDs; (b) DTG curves of CX/PVA and CX/PVA-CDs. 


\subsection{Mechanical Performances}

Figure 5 and Table 1 show the mechanical properties of the as-prepared films. Pure PVA film presents high elongation at break (more than $100 \%$ ) and moderate tensile strength (12.81 $\mathrm{MPa}$, Figure 5a), while pure CX film shows low elongation (2.45\%) and low stress (3.97 MPa, Figure 5a). However, the tensile strength of CX/PVA composite film is significantly improved due to better film formation, with an elongation of $3.67 \%$ and stress of $10.34 \mathrm{MPa}$ (Figure $5 \mathrm{~b}$ ). As compared with CX, the tensile strength of $\mathrm{CX}-\mathrm{CDs}_{1.92}$ nearly doubles $(7.06 \mathrm{MPa}$, Figure $5 \mathrm{a})$, while that of PVA-CD $\mathrm{D}_{1.92}$ only slightly increases (comparing with pure PVA film) (Figure 5a). The difference in the increase of tensile strength can be attributed to the chemical interaction between CDs and CX. The breaking elongations of $\mathrm{CX}-\mathrm{CDs}_{1.92}$ and PVA-CDs 1.92 slightly decrease. The films undergo two tensile stages in the test. The first stage occurs within $2 \%$ tensile strain, where tensile stress increases slowly with strain. In the second stage, the composite film is further stretched and the stress rapidly increases with strain. Non-necking can be observed in the second stage, indicating the homogeneous distribution of CDs in the film. As shown in Figure 5b, the addition of CDs significantly enhances the tensile property of CX/PVA-CDs. The tensile strengths of CX/PVA-CDs $0.48, \mathrm{CX} / \mathrm{PVA}-\mathrm{CDs}_{0.96}, \mathrm{CX} / \mathrm{PVA}-\mathrm{CDs} \mathrm{1}_{1.44}$, and CX/PVA-CDs 1.92 are $12.29,15.83,20.28$, and $22.16 \mathrm{MPa}$, respectively. Especially, with $1.92 \%$ CDs, a remarkable increment of $114.3 \%$ in tensile strength can be obtained. The elastic modulus of the nanocomposite film also significantly increases with CDs content. For example, the elastic modulus of CX/PVA-CDs $1.92(1363.11 \mathrm{MPa})$ is increased by $90.7 \%$ as compared with that of CX/PVA (714.70 MPa). The increase of elastic modulus can be ascribed to stronger interaction between CDs and CX, as indicated in Figure 3) at higher CDs loading. The elongation at break doesn't change significantly. Therefore, CDs can effectively enhance the mechanical strength of the composite films due to its interaction with CX.
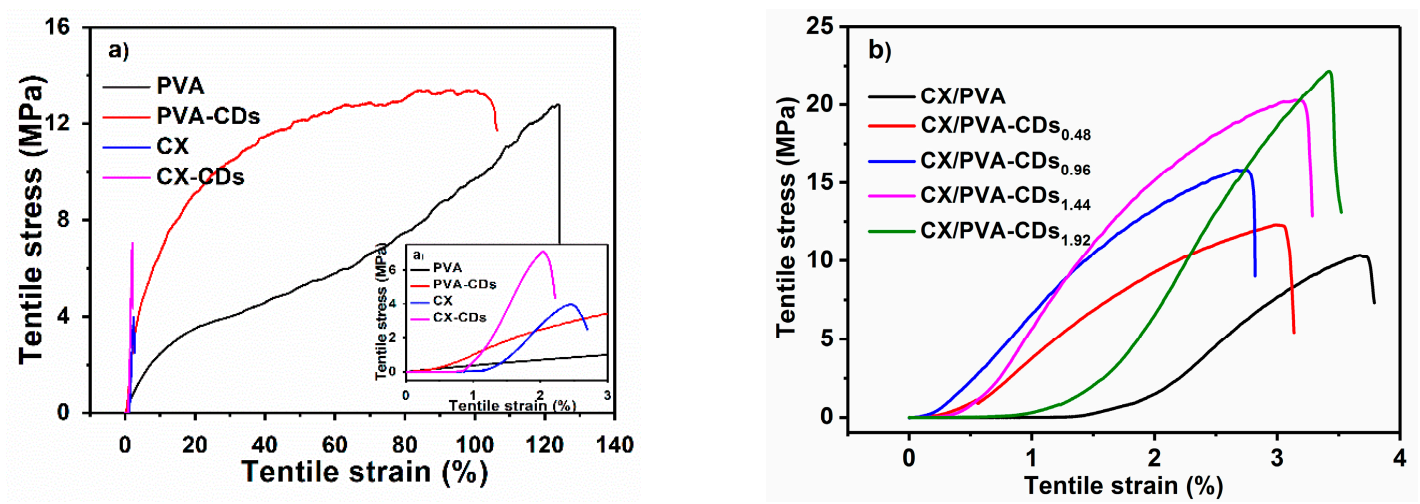

Figure 5. (a) Stress-strain curves of CX, CX-CDs, PVA, and PVA-CDs; (b) stress-strain curves of CX/PVA and CX/PVA-CDs.

Table 1. The breaking strength, elongation, and modulus of CX, PVA, CX/PVA, CX-CDs, PVA-CDs, and CX/PVA-CDs films.

\begin{tabular}{|c|c|c|c|}
\hline Samples & Breaking Strength (MPa) & Breaking Elongation (\%) & Modulus of Elasticity (MPa) \\
\hline CX & 3.97 & 2.45 & 416.45 \\
\hline CX-CDs & 7.06 & 2.04 & 719.31 \\
\hline PVA & 12.81 & 124.22 & 24.19 \\
\hline PVA-CDs & 13.11 & 103.6 & 35.07 \\
\hline CX/PVA & 10.34 & 3.67 & 714.70 \\
\hline $\mathrm{CX} / \mathrm{PVA}-\mathrm{CDs}_{0.48}$ & 12.29 & 2.99 & 690.33 \\
\hline CX/PVA-CDs 0.96 & 15.83 & 2.75 & 869.12 \\
\hline CX/PVA-CDs 1.44 & 20.28 & 3.15 & 1204.75 \\
\hline CX/PVA-CDs 1.92 & 22.16 & 3.42 & 1363.11 \\
\hline
\end{tabular}




\subsection{Optical Performance of CX/PVA-CDs Composite Films}

Figure 6a demonstrates that CX/PVA film shows no significant absorption at light waves higher than $250 \mathrm{~nm}$, while CX/PVA-CDs films have a continuous absorption in the UV region, especially at 260-305 nm, which echoes the absorption spectrum of CDs. The absorption intensity of CX/PVA-CDs composite films in the UV region increases with CDs content. Therefore, CX/PVA-CDs composite films can be used as light conversion films. Figure $6 \mathrm{~b}$ reveals the fluorescence spectra of CX/PVA-CDs 1.92 composite film. It has a strong emission peak at $440 \mathrm{~nm}$ under $360 \mathrm{~nm}$ excitation light, and an excitation peak at $376 \mathrm{~nm}$ under $540 \mathrm{~nm}$ emission light. The results demonstrate that CX/PVA-CDs ${ }_{1.92}$ shows the characteristics of UV excitation and blue light emission, which indicates the potential application of CX/PVA-CDs 1.92 in the light conversion.
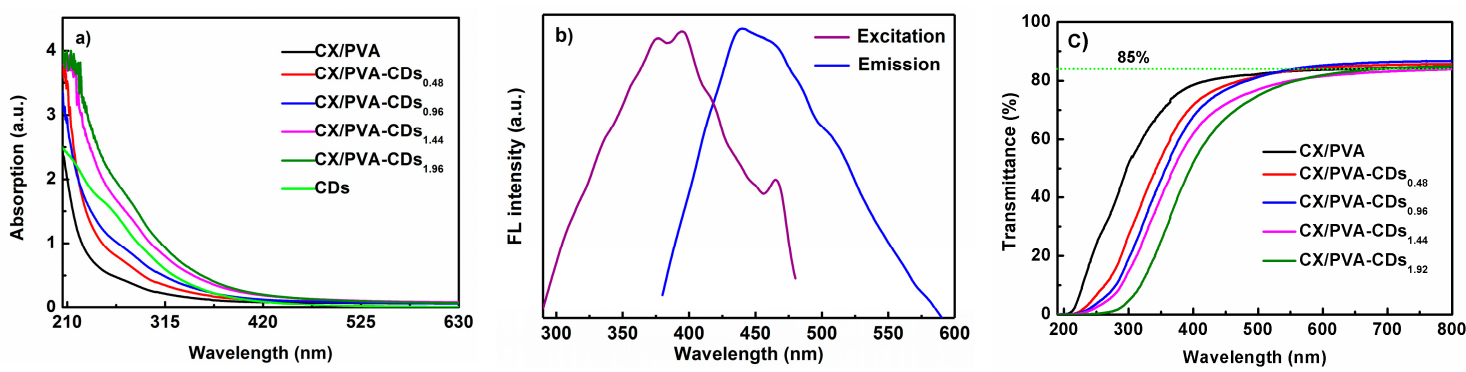

Figure 6. (a) Absorption spectra of CX/PVA and CX/PVA-CDs films; (b) fluorescence spectra of CX/PVA-CDs $1.92 ;$ (c) transmittance spectra of CX/PVA and CX/PVA-CDs films.

Figure $6 \mathrm{c}$ illustrates that the light transmittance of CX/PVA film without CDs is high at the UV region of 200-380 $\mathrm{nm}$, which is reduced after adding CDs, indicating that CX/PVA-CDs composite film can block UV. At the light wave of higher than $600 \mathrm{~nm}$, the light transmittances of CX/PVA-CDs and CX/PVA are similar ( $85 \%)$, suggesting that light beneficial to crops is not blocked. Therefore, CX/PVA-CDs composite film is expected to be used in agricultural planting and food packaging to block UV.

\section{Conclusions}

Xylan-based nanocomposite films with excellent light conversion performances can be prepared through solution mixing method by using xylan-derived CDs as both light conversion regents and nano enhancements. CDs have a good compatibility with matrix and the composite film has uniform structure. The nanocomposite film has better thermal stability. Meanwhile, chemical interaction is formed between carboxymethyl xylan and CDs, which significantly enhances the mechanical strength of the nanocomposite films. Especially, with only $1.92 \%$ CDs, the tensile strength and elastic modulus of the nanocomposite film are increased by $114.3 \%$ and $90.7 \%$, respectively. The nanocomposite film shows UV excitation and excellent optical transmittance, and can effectively convert UV to blue light. These properties render the potential applications of the nanocomposite film in food packaging and agricultural planting.

Author Contributions: Conceptualization, L.Z.; methodology, X.P.; software, Y.Z.; validation, Y.Y. and Y.Z.; formal analysis, Y.Y.; investigation, Y.Y.; resources, Y.Z.; data curation, Y.Y.; writing-original draft preparation, Y.Y.; writing-review and editing, Y.H. and L.Z.; supervision, L.Z.; project administration, L.Z.; funding acquisition, L.Z. All authors have read and agreed to the published version of the manuscript.

Funding: This research was funded by Tip-top Scientific and Technical Innovative Youth Talents of Guangdong Special Support Program (2017TQ04Z837) and Fundamental Research Funds for the Central Universities (2019PY13).

Conflicts of Interest: There is no conflict of interest to declare. 


\section{References}

1. You, Y.; Zhang, H.; Liu, Y.; Lei, B. Transparent sunlight conversion film based on carboxymethyl cellulose and carbon dots. Carbohydr. Polym. 2016, 151, 245-250. [CrossRef] [PubMed]

2. Poudel, P.R.; Kataoka, I.; Mochioka, R. Effect of red- and blue-light-emitting diodes on growth and morphogenesis of grapes. Plant Cell Tiss. Org. Cult. 2007, 92, 147-153. [CrossRef]

3. Mestdagh, F.; Meulenaer, B.D.; Clippeleer, J.D.; Devlieghere, F.; Huyghebaert, A. Protective Influence of Several Packaging Materials on Light Oxidation of Milk. Packag. Technol. Sci. 2005, 32, 9. [CrossRef]

4. Su, X.; Chen, B. Transparent, UV-proof and mechanically strong montmorillonite/alginate/Ca2+ nanocomposite hydrogel films with solvent sensitivity. Appl. Clay Sci. 2018, 165, 223-233. [CrossRef]

5. Sirerol, J.A.; Feddi, F.; Mena, S.; Rodriguez, M.L.; Sirera, P.; Aupí, M.; Pérez, S.; Asensi, M.; Ortega, A.; Estrela, J.M. Topical treatment with pterostilbene, a natural phytoalexin, effectively protects hairless mice against UVB radiation-induced skin damage and carcinogenesis. Free Radic. Biol. Med. 2015, 85, 1-11. [CrossRef]

6. Qi, Y.; Wang, Y.; Yu, Y.; Liu, Z.; Zhang, Y.; Qi, Y.; Zhou, C. Exploring highly efficient light conversion agents for agricultural film based on aggregation induced emission effects. J. Mater. Chem. C 2016, 4, 11291-11297. [CrossRef]

7. Yu, Y.; Wang, Y.; Liu, W.; Jia, X.; Ma, L.; Ren, L.; Xue, M.; Liu, X. Exploration of highly efficient light conversion agents for agricultural film based on the bay-substituted perylene diimides derivatives. Dye. Pigment. 2018, 159, 483-490. [CrossRef]

8. Wu, X.; Zhang, Y.N.; Zhan, S.; Li, J.; Nie, G.; Hu, S.; Yan, C.; Wu, S.; Cheng, S.; Hu, J.; et al. Tracing of dye molecules in living plants through NaGdF4: Yb3+, Er3+ fluorescent nanoprobes. J. Rare Earths 2019, 37, 237-241. [CrossRef]

9. Dawidczyk, T.J.; Walton, M.D.; Jang, W.-S.; Grunlan, J.C. Layer-by-Layer Assembly of UV-Resistant Poly(3,4-ethylenedioxythiophene) Thin Films. Langmuir 2008, 24, 5. [CrossRef]

10. Jing, S.; Zhao, Y.; Sun, R.-C.; Zhong, L.; Peng, X. Facile and High-Yield Synthesis of Carbon Quantum Dots from Biomass-Derived Carbons at Mild Condition. ACS Sustain. Chem. Eng. 2019, 7, 7833-7843. [CrossRef]

11. Yuan, M.; Zhong, R.; Gao, H.; Li, W.; Yun, X.; Liu, J.; Zhao, X.; Zhao, G.; Zhang, F. One-step, green, and economic synthesis of water-soluble photoluminescent carbon dots by hydrothermal treatment of wheat straw, and their bio-applications in labeling, imaging, and sensing. Appl. Surf. Sci. 2015, 355, 1136-1144. [CrossRef]

12. Liu, S.; Tian, J.; Wang, L.; Zhang, Y.; Qin, X.; Luo, Y.; Asiri, A.M.; Al-Youbi, A.O.; Sun, X. Hydrothermal Treatment of Grass: A Low-Cost, Green Route to Nitrogen-Doped, Carbon-Rich, Photoluminescent Polymer Nanodots as an Effective Fluorescent Sensing Platform for Label-Free Detection of $\mathrm{Cu}(\mathrm{II})$ Ions. Adv. Mater. 2012, 24, 2037-2041. [CrossRef] [PubMed]

13. Wu, Z.L.; Zhang, P.; Gao, M.X.; Liu, C.F.; Wang, W.; Leng, F.; Huang, C.Z. One-pot hydrothermal synthesis of highly luminescent nitrogen-doped amphoteric carbon dots for bioimaging from Bombyx mori silk-natural proteins. J. Mater. Chem. B 2013, 1. [CrossRef] [PubMed]

14. Zhang, Y.-Q.; Ma, D.-K.; Zhuang, Y.; Zhang, X.; Chen, W.; Hong, L.-L.; Yan, Q.-X.; Yu, K.; Huang, S.-M. One-pot synthesis of N-doped carbon dots with tunable luminescence properties. J. Mater. Chem. $2012,22$. [CrossRef]

15. Wang, L.; Li, B.; Xu, F.; Shi, X.; Feng, D.; Wei, D.; Li, Y.; Feng, Y.; Wang, Y.; Jia, D.; et al. High-yield synthesis of strong photoluminescent $\mathrm{N}$-doped carbon nanodots derived from hydrosoluble chitosan for mercury ion sensing via smartphone APP. Biosens. Bioelectron. 2016, 79, 1-8. [CrossRef] [PubMed]

16. Yang, G.; Wan, X.; Su, Y.; Zeng, X.; Tang, J. Acidophilic S-doped carbon quantum dots derived from cellulose fibers and their fluorescence sensing performance for metal ions in an extremely strong acid environment. J. Mater. Chem. A 2016, 4, 12841-12849. [CrossRef]

17. Chen, W.; Hu, C.; Yang, Y.; Cui, J.; Liu, Y. Rapid Synthesis of Carbon Dots by Hydrothermal Treatment of Lignin. Materials 2016, 9, 184. [CrossRef]

18. Zhao, Y.; Jing, S.; Peng, X.; Chen, Z.; Hu, Y.; Zhuo, H.; Sun, R.; Zhong, L. Synthesizing green carbon dots with exceptionally high yield from biomass hydrothermal carbon. Cellu 2019, 27, 415-428. [CrossRef]

19. Romani, V.P.; Martins, V.G.; Goddard, J.M. Radical scavenging polyethylene films as antioxidant active packaging materials. Food Control 2020, 109. [CrossRef] 
20. Ren, J.; Wang, S.; Gao, C.; Chen, X.; Li, W.; Peng, F. TiO2-containing PVA/xylan composite films with enhanced mechanical properties, high hydrophobicity and UV shielding performance. Cellulose 2014, 22, 593-602. [CrossRef]

21. Bilgen, S.; Kaygusuz, K.; Sari, A. Renewable energy for a clean and sustainable future. Energy Sour. 2004, 26, 11. [CrossRef]

22. Dar, A.A.; Garai, A.; Das, A.R.; Ghosh, S. Rheological and Fluorescence Investigation of Interaction between Hexadecyltrimethylammonium Bromide and Methylcellulose in the Presence of Hydrophobic Salts. J. Phys. Chem. A 2010, 114, 9. [CrossRef] [PubMed]

23. Srinivasa, P.C.; Tharanathan, R.N. Chitin/Chitosan-Safe, Ecofriendly Packaging Materials with Multiple Potential Uses. Food Rev. Int. 2007, 23, 20. [CrossRef]

24. Yu, S.; Ding, L.; Lin, H.; Wu, W.; Huang, J. A novel optical fiber glucose biosensor based on carbon quantum dots-glucose oxidase/cellulose acetate complex sensitive film. Biosens. Bioelectron. 2019, 146. [CrossRef] [PubMed]

25. Ou, J.; Tao, Y.; Xue, J.; Kong, Y.; Dai, J.; Deng, L. Electrochemical enantiorecognition of tryptophan enantiomers based on graphene quantum dots-chitosan composite film. Electrochem. Commun. 2015, 57, 5-9. [CrossRef]

26. Cuevas, A.; Campos, B.B.; Romero, R.; Algarra, M.; Vázquez, M.I.; Benavente, J. Eco-friendly modification of a regenerated cellulose based film by silicon, carbon and N-doped carbon quantum dots. Carbohydr. Polym. 2019, 206, 238-244. [CrossRef] [PubMed]

27. Sheng, M.; Gao, Y.; Sun, J.; Gao, F. Carbon nanodots-chitosan composite film: A platform for protein immobilization, direct electrochemistry and bioelectrocatalysis. Biosens. Bioelectron. 2014, 58, 351-358. [CrossRef]

28. Zeng, J.; Yan, L. Metal-free transparent luminescent cellulose films. Cellu 2014, 22, 729-736. [CrossRef]

29. Peng, X.-W.; Ren, J.-L.; Zhong, L.-X.; Sun, R.-C. Nanocomposite Films Based on Xylan-Rich Hemicelluloses and Cellulose Nanofibers with Enhanced Mechanical Properties. Biomacromolecules 2011, 12, 3321-3329. [CrossRef]

30. Zhong, L.-X.; Peng, X.-W.; Yang, D.; Cao, X.-F.; Sun, R.-C. Long-Chain Anhydride Modification: A New Strategy for Preparing Xylan Films. J. Agric. Food. Chem. 2013, 61, 655-661. [CrossRef]

31. Yang, Y.; Mei, X.; Hu, Y.; Su, L.; Bian, J.; Li, M.; Peng, F.; Sun, R. Fabrication of antimicrobial composite films based on xylan from pulping process for food packaging. Int. J. Biol. Macromol. 2019, 134, 9. [CrossRef] [PubMed]

32. Qian, Z.; Ma, J.; Shan, X.; Feng, H.; Shao, L.; Chen, J. Highly Luminescent N-Doped Carbon Quantum Dots as an Effective Multifunctional Fluorescence Sensing Platform. Chem. Eur. J. 2014, 20, 2254-2263. [CrossRef] [PubMed]

33. Luís, Â.; Pereira, L.; Domingues, F.; Ramos, A. Development of a carboxymethyl xylan film containing licorice essential oil with antioxidant properties to inhibit the growth of foodborne pathogens. LWT 2019, 111, 218-225. [CrossRef]

34. Yang, P.; Zhu, Z.; Chen, M.; Chen, W.; Zhou, X. Microwave-assisted synthesis of xylan-derived carbon quantum dots for tetracycline sensing. Opt. Mater. 2018, 85, 329-336. [CrossRef]

35. Jiang, X.; Huang, J.; Chen, T.; Zhao, Q.; Xu, F.; Zhang, X. Synthesis of hemicellulose/deep eutectic solvent based carbon quantum dots for ultrasensitive detection of Ag+ and L-cysteine with "off-on" pattern. Int. J. Biol. Macromol. 2020, 153, 412-420. [CrossRef]

(C) 2020 by the authors. Licensee MDPI, Basel, Switzerland. This article is an open access article distributed under the terms and conditions of the Creative Commons Attribution (CC BY) license (http://creativecommons.org/licenses/by/4.0/). 